$107 ; 1920)$. As an example of historical research, the paper on Mendel's work ("Has Mendel's Work been Rediscovered?", Ann. Science, 1 (2), 115 ; 1936), which is almost inaccessible in the original, is of lasting interest, while the relatively trivial paper on the half-drill strip method by Barbacki and Fisher ("A Test of the Supposed Precision of Systematic Arrangements", Ann. Eugen., 7, 189; 1936) seems scarcely worth reproduction without at least a refer. ence to 'Student's' subsequent and not wholly unjustified criticism of it.

The collection will be of immense value to all mathematical statisticians, particularly those of the younger generation who have not had direct contact with the original articles when they appeared. As Fisher himself stresses in the preface, reference to original sources of mathematical research tends to be neglected-indeed, it is only by publications such as the present one that the ordinary student can hope to make any comprehensive study of the works of a single author. In the present instance, the study is of interest and importance, not only in revealing how the subject has developed, but also because many of the results obtained and methods described are still only available in the original papers.

The book is also a worthy monument to Fisher's achievement in mathematical statistics. Even to those who are closely acquainted with his work, it brings fresh realization of its immense scope and the genius that marks so much of it.

From the point of view of a student, there are, of course, defects in the use of collected papers by a single author in the study of a subject, in that only one side of a controversial issue is presented. In such a case what is really required is a collection of papers by different authors dealing with the same subject. The same is true when a subject is developed concurrently by several authors. Perhaps if the method of reproducing scientific papers adopted in the volume is found to be generally acceptable, collections of this kind dealing with specific subjects might be attempted.

F. YATES

\section{POLLEN ANALYSIS}

Text-Book of Modern Pollen Analysis

By Knut Fægri and Johs. Iversen. Pp. 168. (Copenhagen : Ejnar Munksgaard, 1950.) 16 Danish er.

$7 \mathrm{O}$ quote from the preface of this little work :

"Pollen analysis is still a very young science ... . and [it] has developed swiftly during the last 10 years". The aim of the authors, two well-known Scandinavian workers, has been to set forth, fairly exhaustively but simply, the technique in all its aspects and applications. This has been done in seventeen (unnumbered) chapters, which cover the subject thoroughly, from a short historical introduction to the latest suggested aid in pollen-grain identification-a perforated card key. The over-all result is an excellent book that cannot fail to be of very great help to everyone, mature worker or beginner, concerned with the science.

Some points, of course, in my opinion at any rate, invite criticism. In the chapter dealing with the pollen diagram, for example, it would have been more convenient for the reader if the example of a typical diagram (Pl. IX) had been inserted here instead of at the end of the book. As to the merits of different types of diagram, I have always held the opinion that the 'dissolved' (unhappy word) diagram as used by Dr. Godwin and his co-workers has much to recommend it for clarity and directness of appeal. It would have been helpful if an example of this type of diagram covering the (mainly peat) zones of the Post-Glacial Period had been inserted. The omission of any illustration of these zones is indeed strange, since pollen analysis, as we know it, after all was founded on peat; perhaps the answer to this riddle is to be found in the statement on p. 84 of the book, which reads: "For ordinary work one should never analyse peat if any sediment is available". This statement is altogether too sweeping. The 'ordinary' work of pollen analysis dealt, and still deals, with peat. Are we to understand, for example, that the fine work of Jessen on the Irish bogs, so recently published, is of little value? Surely not.

The pollen keys provided are 'artificial' keys, and result in many strange bed-fellows. They deal mainly with the pollen species likely to be found in deposits in north-west Europe. They will doubtless serve their purpose-but, as the authors are at pains to impress on their readers, a pollen herbarium is a sine qua non for the pollen analyst.

The book is pleasingly printed, and the authors acknowledge indebtedness to Miss Jean Allison and Mr. Philip Tallantire for linguistic advice and help in proof-reading. A number of awkward words and phrases have passed uncorrected, but these are not likely to mislead the serious reader. When a second edition is called for, however, as it well may be, the opportunity should be taken of correcting these solecisms-and making a good book better.

J. B. SIMPSON

\section{AMERICAN DECIDUOUS FORESTS}

\section{Deciduous Forests of Eastern North America}

By Prof. E. Lucy Braun. Pp. xiv+596. (Phila delphia and Toronto: The Blakiston Company, 1950.) 10 dollars.

7 HE deciduous forests of eastern North America are treated in this book predominantly from the descriptive point of view, and Prof. E. Lucy Braun adopts as a basis the view that those forests which to-day appear to have been little modified by man can be regarded as indicative of the climax com. munities of the original forest cover.

The deciduous communities dealt with are considered by the author to comprise nine major forest regions based upon physiognomy and similarity of floristic composition. Historic factors are recognized as playing an important part. Thus, the mixed mesophytic forest region of the unglaciated Appalachian plateau is not only particularly the home of the chestnut, Aesculus octandra, and the white basswood, Tilia heterophylla, but is also perhaps significantly the habitat of the tulip tree, of ancient lineage. This region is by far the richest in species, with a number of kinds of trees constituting the canopy, usually more than thirteen even in a small sample area, together with a rich herbaceous vegeta. tion some of the characteristic members of which have contributed to the beauty of gardens in England (for example, Trillium grandiflorum, Erythronium americanum, Phlox divaricata and Tiarella cordifolia). By contrast, the communities of the younger areas, where the forests are attributed to post-glacial immigration, exhibit only about half the number of arboreal species in the forest canopy, and the subordinate layers are floristically far less varied. 